MARKETING AND BRANDING
RESEARCH $\begin{gathered}\text { INDUSTRIAL } \\ \text { MANAGEMENT } \\ \text { INSTITUTE }\end{gathered}$

\title{
Investigating the relationship between personality traits and general health with addiction to purchase (obsessive purchase)
}

\author{
Seyed Mehdi Sadr Bafghi', Mohammad Mirmohammadi Sadrabadi ${ }^{2 *}$, Hamed \\ Shakerian $^{3}$ \\ ${ }^{1} \mathrm{PhD}$ Student of Industrial Strategy, Department of Industrial Management, Science and Research Branch, \\ Islamic Azad University, Tehran, Iran \\ ${ }^{2}$ Department of Accounting, Yazd Branch, Islamic Azad University, Yazd, Iran \\ ${ }^{3} \mathrm{PhD}$ Student of Production and Operations Management, Department of Industrial Management, Tabriz \\ Branch, Islamic Azad University, Tabriz, Iran
}

\begin{abstract}
Keywords:

Relationship

Marketing, Financial

Mechanism,

Relationship Quality,

Customer Sentiment,

Customer Loyalty

Correspondence:

m.mir.m2010@gmail.com

The aim of this study was to investigate the relationship between personality traits and general health with addiction to purchase (obsessive purchase) among the students of Islamic Azad University of Yazd. Using personality traits and mental health variables as independent variables and addiction to purchase as the dependent variable, hypothesis of research is formed. The study was an applied research adopting a survey method and it was based on survey correlation using questionnaires. The statistical population of this research was students of business management. Simple random sampling method was used and a total valid sample of 224 was collected. Data analysis using the PLS software was done and the results showed that the trait neuroticism, flexibility, agreeableness trait, somatic symptoms and impaired social functioning as personality characteristics do not have significant effect on obsessive purchase but extraversion personality characteristic have a significant impact on obsessive purchase and the impact value is 0.20 and positive. Therefore, it can be concluded that as soon as the members have more extraversion characteristic, their obsessive purchase increases and compulsive personality trait has a significant impact on obsessive purchase. The impact value is 16.0 and negative; so we can conclude that if people have less responsibility, obsessive purchase will increase. Anxiety has a significant impact on obsessive purchase and the impact value is 24.0 and positive. So it can be stated that as soon as people have more anxiety, the obsessive purchase increases.
\end{abstract}




\section{Introduction}

Koran et al. (2006) argued that when people are not able to control their purchasing, they frequently purchase unnecessary goods or more than their financial ability and spend more time than they had intended for purchasing. Purchasing is a small part of daily activity for most people but it can be the main part of life for some people. Compulsive buying is dark side of consumer behaviour and one of purchasing behaviours that consumer pays attention to it. Compulsive buying includes repeating persistent purchase that it is the first response to negative feelings and events. One interesting discussion in marketing is making decision for consumer purchasing and his purchasing behaviour and this behaviour has positive and negative aspect in welfare and it is affected by personal and social characteristics such as education, economic status, emotional relations, and social environment (Taheri Kia \& Naderi, 2012). Personality characteristic is one of the main sources of our making decision that in this article, effects of personality in obsessive purchasing are discussed and it is anticipator of consumers' behaviour in the future and present and is a guide map for planning and doing strategic plans. Manner of purchasing and attention to enjoying or benefiting aspect of purchase are different between men and females and people personality, behaviour, habits, motivation, and response to stimulus are different. Personality inspired from two origins, namely changeless hereditary and adaptation to situation. The article studies five major factors of personality including psyche, extraversion, experience acceptance, conscience, and agreement acceptance. People personality has an important role in the way of purchasing but economic status, religion, social status, policy of government and cultural issues have directly and indirectly more effects on making people personality and their purchasing behaviour (Gohari \& Heidarzadeh Hanzaee, 2014).

Accordingly, mood disorders have several effects on mental health and well-being and depression is a mood disorder that substantially impacts on social relations between the individual and job. Depressed people experience some feelings from sadness to irritability, frustration, and sense of helplessness. They have suicidal tendencies and experience anxiety in emotional, cognitive-behavioural, and spiritual fields (Sadok \& Sadok, 2007). Frankel discussed that having goal and accepting responsibility in life lead to mental health. On this basis, a lot of researches were conducted in the field of meaning therapy on mental and physical illness and its positive effects have been approved. With the educational supports and increasing family awareness, mental health and sense of well-being can be increased and family relationships can be strengthened and welfare and improvement of family members can be provided. Today, purchase precinct forms an important part of consumer's behaviour and from the perspective of scientists of psychological and behavioural science acquisition of knowledge about purchase to predict and control humans' behaviour is useful. Marketing researchers and academicians also seek to identify factors affecting the behaviour of consumer purchasing and they try to be able to maintain their competitive position in today's meta-competitive market by further understanding of consumers (Silvera, Lavack, \& Fredric, 2008). The aim of this study is the influence of personality characteristics and mental health on purchasing behaviour due to qualitative and quantitative criteria simultaneously. The main purpose of this study is mechanism for decision-making in market. This study proposes a method to identify better understanding of consumer behaviour through identifying 
personality characteristics of mental well-being (mental health) of consumers in addiction to purchase (compulsive buying). The issue is that how does personality characteristics of mental well-being impact on type of students' purchase?

\section{The Literature Review}

\section{Compulsive Buying}

Faber and O'Guinn (1989) define compulsive buying (addiction-like) as chronic repetitive purchase that is likely to change in initial reaction to the events and emotions. Koran et al. (2006) added that when people are not able to control their purchase, they frequently purchase unnecessary goods or more than their financial ability and spend more time than they had intended for purchasing. Purchase for young people is considered as an activity for leisure time, emotional management or it is a way to express their identity and behaviour of uncontrollable purchase related to compulsive buying (addiction-like) and too much purchases (Koran et al., 2006). There is a set of basic characteristics for a variety of compulsive buying (addiction-like); these characteristics include individual and psychological characteristics that depend on the type of purchase behaviour. Some of these characteristics can be referred to sudden loss of control in purchase behaviour and making problem in behaviour after purchasing, existence of a stimulus, sudden motive, and lack of accepting negative consequence in continuation of purchase, repeated failure to control or modifying purchase behaviour (Faber, O'Guinn, \& Krych, 1987).

Practical studies were done on emotions that compulsive buyers experienced it. Emotions are very important for compulsive buyers. Some studies were done on compulsive buyers' emotions by Faber and Christenson (1996) and Dittmar (2005). These studies were conducted on different moods of compulsive buyers. Based on these studies, compulsive buyers encounter positive and negative emotions before purchasing and also, during and after purchasing. Positive emotions are activated during the process of purchasing and compulsive buyers forget negative emotions before purchasing by seeing stores and goods. Therefore, compulsive buyers feel joyful, lively, high self-esteem, joy, and acceptance during the purchasing process and according to Faber and Christenson (1996) compulsive buyers feel happy, excited, and powerful during the purchasing process. They experience the sense of pleasure, pride, and satisfaction in a short period of time, but after a short time these positive emotions change to negative feelings and emotions such as shame, depression, anxiety, and guilt because of the money that is spent (Saraneva \& Sääksjärvi, 2008).

The results of the study by Veludo-de-Oliveira, Augusto Falciano, M., and Villas Boas Perito (2014) on "Effects of Credit Card Usage on Young Brazilians' Compulsive" that was done over 365 young students who use credit card in two cities in Sao Paolo in Brazil shows that using credit cards is effective in increasing anxiety in the behaviour of compulsive buying and using credit cards is a mediator between the behaviour of compulsive buying and three variables, namely power of credibility, saving time, and anxiety. Following this, use of credit cards is not related to distrust (sensitivity on price) in compulsive buying (Tania Modesto et al., 2014). Lee, Chang, Lin, and Cheng (2014) conducted a study on affecting users' characteristics due to obsessive using of smart phones and innovation in the smart phones. Results of obsessive use are more approved because of uncertain space of phone, social 
anxiety, understanding high touch speed, and need for call. Effect of uncertain space of phone in obsessive use of smart phones by males is stronger; on the other hand, the social anxiety among females in obsessive use of smart phones is stronger. It was also found that understanding high touch speed in obsessive use of smart phones is stronger and direct effect of being physical is more than understanding touch speed in use of smart phones (Lee et al., 2014). James and Roberts Camille (2012) in a study tried to get a better understanding of compulsive buying as a solution for this type of purchasing among low-experienced youngsters. Results of the study on a sample of 82 students in the seventh grade ranging in age from 12 to 13 years old in the United States America indicates that compulsive buying among low-experienced youngsters is related to stress but there is no interaction between stress and gender and compulsive buying does not depend on gender.

\section{Personality and Its Characteristics}

Maddi (1989) considers personality as a stable set of tendencies of characteristics that determines people's behavioural-psychological similarities and differences and it easily cannot be understood as a result of biological and social pressures of time. The character traits are the first detection guide of cognitive-emotional status of people and they influence on social-emotional roles and interpersonal behaviours of people (Moynihan \& Peterson, 2001). Character is defined as organization within emotional, cognitive, and conceptual systems of individual that defines person's unique response to the environment (Dole \&Schroeder, 2001). Personality characteristics and character have effect on distinctive behaviour of purchase, habits, and motives and have different response to a stimulus. Individual differences in environmental resources include personality coming from two initial empirical and stable calibrated sources, situational references, specialized strategy, adapting self-assessment of transferable quality, hereditary sources, and temporal and local changes in choice. Choice depending on frequency is negative and has a balance direction (Gohary \& Heidarzadeh Hanzaee, 2014). According to White, Newman, Cromwell, and Lindemann (2002), personality characteristics can be used to predict behaviors and performance of healing people. Gohary and Heidarzadeh Hanzaee (2014) examined the relationship between personality characteristics and purchasing motive with variables such as unplanned purchase, purchasing with pleasure, and profit-oriented purchasing among university students. The results of study over 247 male and female students in Qazvin and Urmia in Iran indicated that responsibility, acceptance of experience, and shyness are predictor factors for compulsory purchase, unplanned purchase, and profit-oriented purchase.

\section{Five Factor Model of McKri and Kosta}

McCrae and Costa (1989) considered a program that detected five famous factors of characteristic known as "five powerful factor" or "big five". They detected five super traits that placed at the top of personality characteristics pyramid and each has six special features and in general, they have achieved 30 personality characteristics (Figure 1). Researches in recent years show that five personality dimensions are the basis of other characteristics (Caplan, 2003). Figure 1 presents the hierarchy of character system. 


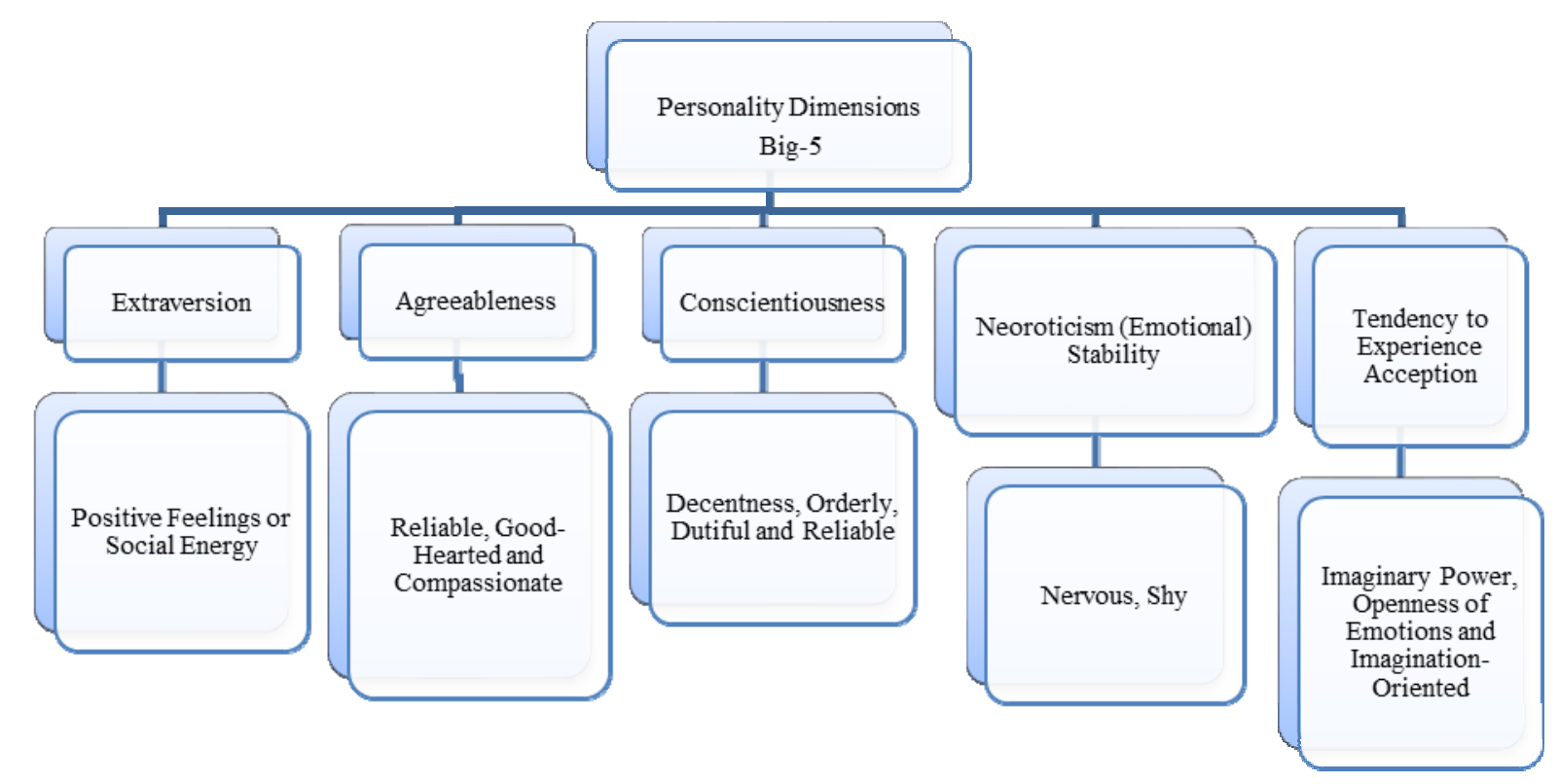

Figure 1. The hierarchy of character system

Ye, Yu, and Li (2012) conducted a study over 14 male students and 134 female students. In the first case, self-esteem and life satisfaction were used to predict and in the second case, independent variable of social-economic status were used to predict self-esteem and life satisfaction. The results showed that self-esteem subsequently effects on life satisfaction, but the reverse is not true (Ye et al., 2012). Ergin (2010) in his research that was conducted in Turkey examined a sample of 314 people and the results revealed that compulsive buying (addiction-like) is an unusual consuming behaviour and a severe inability to control in the urge to purchase goods and services. The experimental results also showed that Turkish men and women are different in compulsive buying and some factors such as age and gender have a strong relationship with the behaviour of compulsive buying (Ergin, 2010). Many psychologists believed that the main construction of human character is showed by five total traits, namely extroversion, agreeableness, conscientiousness, neuroticism (emotional stability), and openness. These traits are formed among people partly due to inherent tendencies and partly due to growing up in a special environment. Being familiar with five main traits is important because all these traits affect people's performance. Interpretation and implication of these personality factors cause to have special consideration to important fields. Although some of these features are inherited, most people are able to reinforce personal development of these features in them. The well-known super traits are as follows (Buchanan, 2000):

\section{Emotional Stability}

This is related to individual's ability to tolerate stress. People with neuroticism feature have low emotional stability. These people are nervous, disappointed, shy, vulnerable, and hasty and they have stress. People with emotional stability usually have negative mood in their work and generally they have negative attitudes towards their work. 


\section{Extroversion}

Extroversion refers to a set of traits and that is a degree that individual is full of energy, daring, active, thrill-seeking and he has enthusiasm, self-confidence, and positive feelings. Extroverted people have tendency to be social, emotional, and friendly and they usually deal better with different people.

\section{Openness to Experience or Experienced Advice}

The last dimension shows the interest of people towards newness and acquiring new experiences. People with these features have power of imagination, interest in art manifestations, open feelings, and ideas, and they are curious about the ideas of others and also, they are action oriented. People who have openness to accept experiences, they can be useful for jobs that there are high changes and evolutions or jobs that need innovation or substantial risk.

\section{Agreeableness}

This feature is related to people's tendency to be the same with others. People with the feature of agreeableness are reliable, honest, altruistic, compassionate, followers, humble, and goodhearted and they have the feature of sacrificing, and agreeable people usually guide teams. They also are suitable for teaching, psychological affairs, counselling in jobs, and social activities.

\section{Conscientiousness or Conscience}

This is the measure of reliability. A person with high conscientiousness is decentness, orderly, dutiful, goal seeker, punctual, reliable, and he has self-discipline. Conscientiousness is important and useful in many organizational situations and it is a proper indicator for predicting performance in many occupations because tendency of these people is more to achieve opportunity.

\section{Mental Health}

Mental health means satisfaction, healthier psyche, and compliance of normative standards of society. Sapington, Pharr, Tunstall, and Rickert (1997) considers mental health as good compatibility, sense of well-being, and flourish of personal talents. From the perspective of Frankel et al. (1997), mental health is the lack of existential vacuum and depression resulted from meaninglessness and non-responsibility. According to Frankel, mental health and happiness could be achieved if people experience a goal and meaning in their life and therapist should help to discover this meaning. Frankel names it as "self-transcendence" and it is interaction to his research theory (Sadock, Kaplan, \& Sadock, 2007).Mental health in different cultures refers performing based on community norms and compliance with them in order to flourish talents and adapt to different situations for cheering ourselves and others (Aghajani, 2002). Karaś, Cieciuch, and Keyes (2014) in a study on validity of personality characteristics and adaptation of Polish compliance with mental health that was done among 2115 people including four groups of elementary school students, vocational students, secondary education students and higher education students in the schools of Poland showed that welfare is an important factor affecting mental health in a short interconnected form. The 
study has evidence based on positive effect of welfare (emotional, social and psychological) on mental health in a short interconnected form. This study also confirms the effect of welfare on mental health in a short interconnected form over four groups of elementary students with the basic education, vocational students, secondary students, and higher education students (Karaś et al., 2014).

\section{Research Hypotheses}

According to the theoretical foundations, the main research hypothesis can be presented as follows:

- Personality characteristics and mental health have effect on addiction to purchase (compulsive buying) of students of management department.

In addition, the following hypotheses are corollary to the main hypothesis:

$\mathbf{H}_{1}$ : Personality characteristic of emotional stability has effects on compulsive buying.

$\mathbf{H}_{2}$ : Personality characteristic of extroversion has effects on compulsive buying.

$\mathbf{H}_{3}$ : Personality characteristic of openness to experience has effects on compulsive buying.

$\mathbf{H}_{4}$ : Personality characteristic of agreeableness has effects on compulsive buying.

$\mathbf{H}_{5}$ : Personality characteristic of conscientiousness has effects on compulsive buying.

$\mathbf{H}_{6}$ : Physical signs affect compulsive buying.

$\mathbf{H}_{7}$ : Disorder in social performance has effects on compulsive buying.

H8: Anxiety had effects on compulsive buying.

H9: Depression effects on compulsive buying.

\section{Method}

The study is an applied research adopting a correlational method that examines the relationship between variables. Method of investigation is metrical which is regarded as a type of questionnaire for data collection. Statistical population of the research consists of the students of management department of Islamic Azad University, Yazd branch that its number is limited. The considered number is selected randomly and 224 questionnaires of the prepared questionnaires are received by the researcher. Since the sampling procedure used in the study is simple random sampling and due to the lack of access to all students at the university level, sampling method is used. Morgan table is used to determine sample size which was obtained as 208. The researcher distributed 2400 questionnaires and finally 224 questionnaires were achieved by the researcher after tracking.

Time domain including data collection and analysis of questionnaire consists of a period of 6 months. To collect data related to hypothesis and questions of the research, field method was used and data collection tool is questionnaire. Closed questions were used in the questionnaire, because closed questions help participant make decision faster by choosing one of the provided options and they also make simpler extracting of data that should be analyzed for the researcher. 


\section{NEO Personality Questionnaire}

Personality questionnaire NEO-FFI known as NEO was designed by McCrae and Costa (1989) and it was manipulated and used in Iran by Cornou, Gueguen, Bard, and Haghshenas (2004).

\section{Mental Health Questionnaire}

Goldberg and Hillier (1979) designed and developed general health questionnaire (GHQ) for screening non-psychotic mental disorders in treatment centers and community. In the present study, the 28-item form of general heath questionnaire designed by Goldberg and Hiller was used which has the advantage of being designed for all people in society. The questionnaire has four sub-scales that each scale has 7 questions. Four sub-scales of questionnaire are about social functioning and depression syndrome.

To measure validity there are various methods that in this research content-validity method was used before collecting data. Thus, the questionnaire was reviewed and evaluated by supervisor and advisor professors to assess its compliance with social norms and the aims of the research. Since the closed question questionnaire extracted from valid scientific and scholarly journal was used, the questionnaire was evaluated by professors; therefore, it is valid. To determine the reliability of questionnaire, Cronbach's alpha was used. If alpha coefficient is greater than 0.7 , questionnaire has acceptable reliability. Table 1 shows the measuring questions of the questionnaire reliability.

Table 1

Measuring Questions of the Questionnaire Reliability

\begin{tabular}{lcc}
\hline Variable & Number of Questions & Cronbach's Alpha \\
\hline Compulsive buying (CB) & 7 & 0.79 \\
Physical symptoms (SS) & 7 & 0.83 \\
Anxiety (Anx) & 7 & 0.86 \\
Social Disorder (SD) & 7 & 0.90 \\
Depression (Dep) & 7 & 0.92 \\
Total questionnaire & 79 & 0.88 \\
\hline
\end{tabular}

Table 1 provides Cronbach's alpha and number of questions related to total questionnaire and variables of the questionnaire. Since value of Cronbach's alpha of total questionnaire and variable is more than 0.7 , the test has acceptable reliability.

\section{Results}

In the present study, description of demographic data is done using descriptive statistics, frequency tables, pie charts, and pie graphs and to study variables, according to the medium measure scale, one sample t-test was used and data were analyzed by SPSS 18 software. Verifying the relationships between variables and factors is done through confirmatory factor analysis and PLS modelling technique using PLS2Smart software that is a modelling technique of variance-based path and it provides the possibility of studying and measurements simultaneously. This method is used when the model is complex and sample size is small or the variables are not normal.

In methodology of structural equation model, at first, it is necessary to study the validity of construction to determine the selected items for measuring its considered variables to be accurate. For this purpose, confirmatory factor analysis (CFA) is used. In accordance with the 
results of this study, all items had t-statistic greater than 1.96. So, none of the items are removed from the model. Thus, procedure continued with all of the items (questions). On the other hand, based on the factor loading, indicator that had the highest factor loading, it had a greater share in measuring the variable and indicator that had smaller coefficients, it had a smaller share in measuring the related structure.

\section{Model Outputs (Path Coefficients and T-Statistic)}

Using the internal model, the hypothesis can be discussed. By comparing t-value calculated for coefficient of each path, it can be used to approve or reject the hypotheses. Thus, if the absolute value of the t-statistic is greater than 1.96 , it is significant at $95 \%$ confidence level and if t-statistic value is greater than 2.58 , path coefficient is significant at $99 \%$ confidence level. Results of conceptual model test in the research are shown in significant status of coefficients in Figure 2.

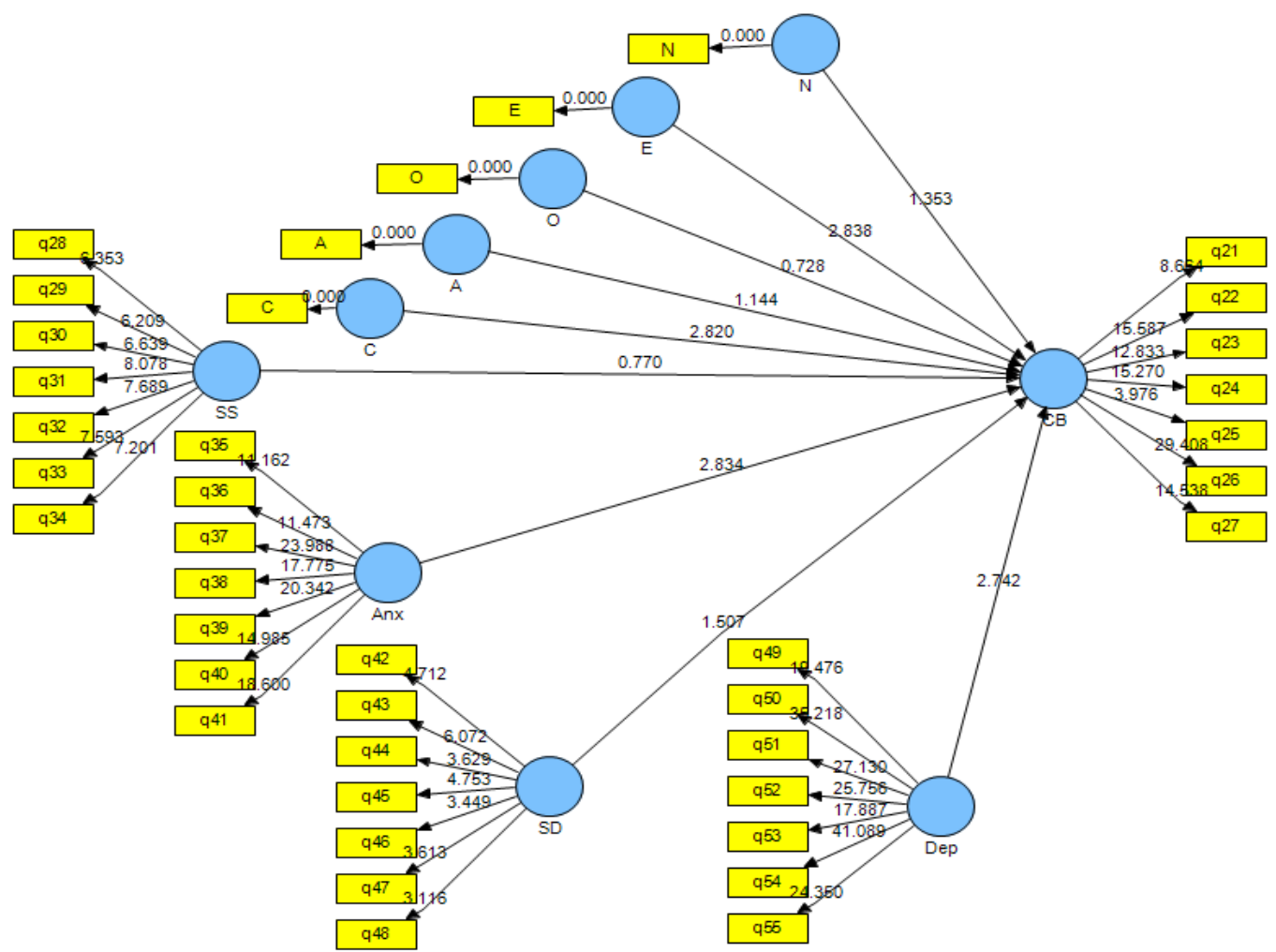

Figure 2. Model in significant numbers status (t-value)

The existed numbers on the paths indicate t-value for each path. To examine the significance of coefficient of each path, it is necessary that the t-value of each path to be greater than 1.96. In this analysis, t-value was higher than 1.96 for personality characteristic paths of extroversion, conscientiousness, anxiety, and depression to compulsive buying and as a result, it is significant at $95 \%$ confidence level. Figure 3 represents the model in path coefficients status. 


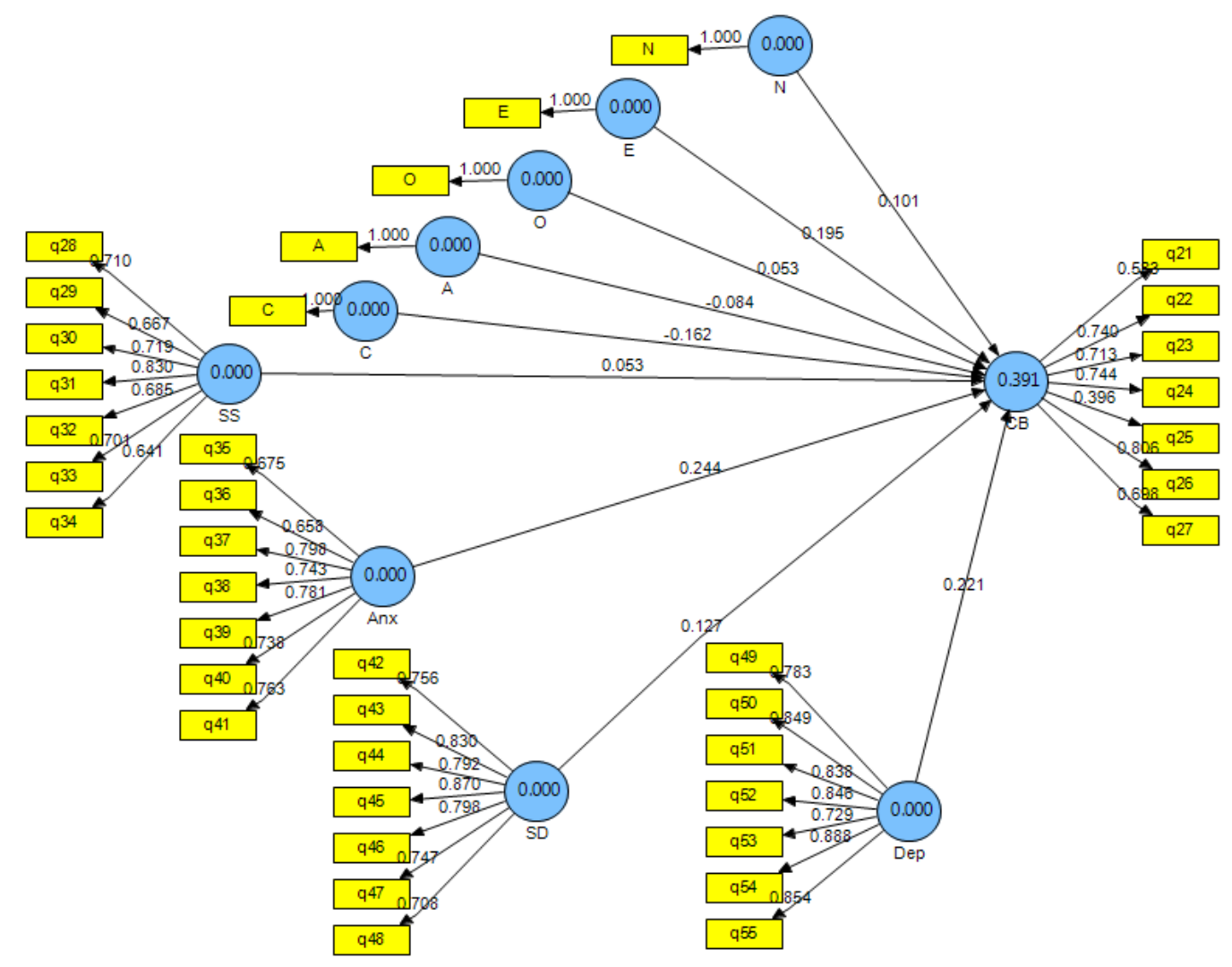

Figure 3. Model in path coefficients status

In fact, numbers written on the lines are the Beta coefficients resulted from regression equation among the variables that is path coefficient. The amounts of coefficient R2 is presented as numbers in each circle. The predictive variables of coefficient R2have been entered via the arrow to the circle. The determining coefficient for the variable of compulsive buying is estimated as 0.39 and indicates personality characteristic variables of emotional stability, extroversion, openness to experience, agreeableness, conscientiousness, physical symptoms, anxiety, disorder in social performance, and depression that all together can describe $39 \%$ of compulsive buying changes. According to the value of standard coefficient and t-statistic, it can be said that anxiety variables (0.24), depression (0.22), personal characteristic of extroversion (0.19), and personality characteristic of conscientiousness (0.16 ) have the highest impact on the variable of compulsive buying. Personality characteristic of emotional stability, openness to experience, agreeableness, physical symptoms, and disorder in social performance did not have significant effect.

\section{Internal Model (Structural Model)}

Hypotheses were examined in the form of internal model and the path of structural model was evaluated. In order to evaluate significance of path coefficient or beta, significance of $t$-value should be considered for each path coefficient. So the bootstrap method was used that for this purpose, resampling in both 500 and 800 modes were simulated. The results showed that in both cases there is no change in meaningfulness or non-meaningfulness of parameter and the results are strongly valid. Table 2 exhibits the direct linear effect of research variables in model. 
Table 2

Direct Linear Effect of Research Variables in Model

\begin{tabular}{|c|c|c|c|c|c|c|}
\hline \multirow{2}{*}{ Path } & \multirow{2}{*}{ Beta } & \multirow{2}{*}{ Average } & \multirow{2}{*}{ Standard Error } & \multicolumn{3}{|c|}{ T-Statistic or Re-Simulating } \\
\hline & & & & 800 & 500 & 200 \\
\hline $\mathrm{CB} \leftarrow \mathrm{N}$ & 0.10 & 0.10 & 0.07 & 1.41 & 1.38 & 1.35 \\
\hline $\mathrm{CB} \leftarrow \mathrm{E}$ & 0.19 & 0.19 & 0.06 & 2.94 & 2.83 & 2.83 \\
\hline $\mathrm{CB} \leftarrow \mathrm{O}$ & 0.05 & 0.05 & 0.07 & 0.72 & 0.72 & 0.72 \\
\hline $\mathrm{CB} \leftarrow \mathrm{A}$ & -0.08 & -0.08 & 0.07 & 1.07 & 1.11 & 1.14 \\
\hline $\mathrm{CB} \leftarrow \mathrm{C}$ & -0.16 & -0.16 & 0.05 & 2.79 & 2.66 & 2.82 \\
\hline $\mathrm{CB} \leftarrow \mathrm{SS}$ & 0.05 & 0.05 & 0.06 & 0.75 & 0.71 & 0.76 \\
\hline $\mathrm{CB} \leftarrow \mathrm{SD}$ & 0.12 & 0.12 & 0.08 & 1.63 & 1.59 & 1.50 \\
\hline$C B \leftarrow A n x$ & 0.24 & 0.24 & 0.08 & 2.59 & 2.64 & 2.83 \\
\hline CB ŁDep & 0.22 & 0.22 & 0.08 & 2.74 & 2.69 & 2.74 \\
\hline
\end{tabular}

According to t-statistic value for paths, it is greater than 1.96 for the personality characteristic paths of extroversion, conscientiousness, anxiety, and depression to compulsive buying that indicates it has significant impact on personality characteristic paths of extroversion, conscientiousness, anxiety, and depression to compulsive buying at 95\% confidence level. Following this, personality characteristic paths of emotional stability, openness to experience, agreeableness, physical symptoms, and disorder in social performance to compulsive buying do not have significant effect.

\section{Research Hypotheses Test}

After studying the original model, research hypotheses were evaluated. If the absolute value of t-statistic is smaller than 1.96, null hypothesis is concluded and if absolute value of $\mathrm{t}$ statistic is greater than 1.96, null hypothesis is rejected and the related hypotheses are tested in this section. Table 3 shows the results of research hypothesis testing.

Table 3

Results of Research Hypotheses Testing

\begin{tabular}{cccc}
\hline Hypothesis & T-Statistic & Table Value & Conclusion \\
\hline 1 & 1.35 & 1.96 & Not Significant \\
2 & 2.84 & 1.96 & Significant \\
3 & 0.73 & 1.96 & Not Significant \\
4 & 1.14 & 1.96 & Not Significant \\
5 & 2.82 & 1.96 & Significant \\
6 & 0.77 & 1.96 & -0.05 \\
7 & 1.51 & 1.96 & -0.16 \\
8 & 2.83 & 1.96 & Not Significant \\
9 & 2.74 & 1.96 & Not Significant \\
\end{tabular}

\section{Discussion}

Purchase behaviour is done as an activity for entertainment and relief from daily stress and anxieties. In fact, purchasing is a kind of entertainment that is in relation to the feelings of consumers. That is why most buyers search for hours to shop in shopping centers to change their arduous daily life by good experience of buying. When the action of buying is strong, it is changed to compulsive buying (addiction-like). Much of studies that have been conducted on compulsive purchases (addiction-like) indicate that this type of buying is done more among young people. Buying is an activity for leisure, managing emotions or a way for expressing their identity among young people. Identity is various dimensions of an individual's characteristics that is organized coordinately and satisfactorily in him. To achieve identity, it is necessary to operate our continuous efforts to be able to know our different 
characteristics. We should understand the features of identity and have continuous and coordinate effort to achieve them. Therefore, search for identity implies that a person recognizes what is important and valuable for him and implies adjusting criteria in which he can evaluate and guide his behaviour and others' behaviour based on them. In addition, this search also involves the development of self-sufficiency and competence. We try to get an imagination of ourselves through collecting values and evaluating them and as values expressed by parents, teachers, and peers are closer together, identification procedure proceeds easier and community in identification can have an important role. In a simple society that coordinating patterns and social roles are limited within it, identification can be done easily, but in a complex society that is changing rapidly, identification is difficult and long for many people and in such a situation to understand how to behave and what to follow in life, we should consider unlimited jobs. Therefore, consumer's behaviour arises which is one of the important marketing topics and branches. In the field of consumer's behaviour, many types of purchases arise that one of its classification includes planned buying and unplanned buying. Unplanned buying is a comprehensive aspect of consumer's behaviour and a significant center in marketing activities. Variety in productions makes consumers and buyers to have compulsive buying. In this regard, each manufacturer tries to attract buyers' attention towards his productions. Today, changes increase the complexity of consuming and this issue makes an atmosphere that is more favorable to increase compulsive buying than in the past. A person who has mental health has the ability of adaptation to the problems during the growing periods; he is adaptable and has positive sense of harmony. Accommodation is the feeling of behavioural health with the inner feeling (Bani Jamal Vahedi \& Ahadi, 1991).

\section{Conclusion}

The first hypothesis about the relationship between personality characteristics of emotional stability and compulsive buying was stated and tested. The results of this hypothesis did not suggest significant and direct effect of personality characteristic of emotional stability on compulsive buying. The second hypothesis about the relationship between personality characteristic of extroversion and compulsive buying was stated and tested. The results of this hypothesis suggested significant and direct effect of personality characteristic of extroversion on compulsive buying. Third hypothesis about the relationship between personality characteristic of openness to experience and compulsive buying was stated and tested. The results of the analysis did not suggest significant and direct effect of personality characteristic of openness to experience on compulsive buying. The results of the relationship between personality characteristics of openness and emotional stability in experience and compulsive buying are consistent with the results of a study by Zargar (2013). The fourth hypothesis about the relationship between personality characteristic of agreeableness and compulsive buying was stated and tested. The results of the analyzing this hypothesis did not suggest significant and direct effect of personality characteristic of agreeableness on compulsive buying. The fifth hypothesis about the relationship between personality characteristic of conscientiousness and compulsive buying was stated and tested. The results suggested significant and direct effect of personality characteristic of conscientiousness on compulsive buying. In another research by Emamipour and Sabzmeydani (2009) the relationship between personality characteristics and perfectionism with students' general health was discussed. 
Their study approved the idea of existence of a relationship between general health and conscientiousness. The sixth hypothesis about the relationship between physical symptoms and compulsive buying was stated and tested. The results of the analysis of this hypothesis did not suggest significant and direct effect of physical symptoms on compulsive buying. The seventh hypothesis about the effect of disorder in social performance on compulsive buying was discussed and tested and the results did not suggest the significant relationship between disorder in social performance and compulsive buying. Following this, the results of the eighth hypothesis referring to the effect of anxiety on compulsive buying suggested a significant relationship between anxiety and compulsive buying. Tania Modesto et al. (2014) concluded that using credit card is effective in increasing anxiety and compulsion in compulsive buying behaviour.

The ninth hypothesis of the research about the effects of depression on compulsive buying was discussed and tested. The results of the analysis recommended that depression has significant effect on compulsive buying. James and Roberts Camille (2012) in a study on investigating stress, gender, and compulsive buying among youngsters with low experience showed that stress and anxiety have a significant relationship with compulsive buying. In general, the results of the present study in the field of effects of anxiety and depression on mental health, extroversion, and conscientiousness variables as dimensions of personality characteristics with other studies were observed; much of these studies indicated that anxiety, depression, extroversion, and conscientiousness have a significant effect with compulsive buying. What is observed in studying and investigating in this research and is important from the perspective of researcher is paying attention to this point that education can be a scientific basis to intervene in compulsive buying. The present intervening is considered as a short time and compact intervening.

Although psychologists and socialists consider being eager to buy as a deniable fact, they believed this phenomenon has exceeded beyond the necessity in today's society. Accordingly, addiction to buying (compulsive buying) is considered as a major and social issue and according to the importance of the issue and its negative consequences in individual and social life, it is suggested to officials to create a kind of culturing with education of life skills through media and social entities in the way that this kind of culturing is defined based on style and attitude of university students' life according to religious trainings and traditions and based on today's needs of society. Finally, the sense of satisfaction, life expectancy, and happiness will be reinforced by this culturing. Naturally, people with addiction to buying (compulsive buying) are in need of treatment and rehabilitation services. It is suggested to psychological clinics and centers to have a special attention in their advising to extroverted or non-responsible people; so that, these people would be aware of the consequences of compulsive buying (addiction to buying). It should be tried to behave with these people in a way that they are not frustrated, because these people due to pride and because they are proud of their greatness to others have compulsion in their purchases and they may buy more than their needs.

\section{References}

Aghajani, M. (2002). Investigating the effect of educating life skills on mental health and control source of youngsters (Unpublished master's thesis). Al-Zahra University. 
Bani Jamal Vahedi, S., \& Ahadi, H. (1991). Mental health and mental retardation. Tehran: Ney Publication.

Buchanan, T. (2000). Potential of the internet for personality research. In M. H. Birnbaum (Eds.), Psychological experiments on the internet (pp. 121-140). San Diego, CA: Academic Press.

Caplan, B. (2003). Stigler-Becker versus Myers-Briggs: Why preference-based explanations are scientifically meaningful and empirically important. Journal of Economic Behavior \& Organization, 50(4), 391-405.

Cornou, C., Gueguen, P., \& Bard, P. Y., \& Haghshenas, E. (2004). Ambient noise energy bursts observation and modelling: Trapping of harmonic structure-soil induced - waves in a topmost sedimentary layer. Journal of Seismology, 8(4), 507-524.

Dittmar H. (2005). Compulsive buying-a growing concern? An examination of gender, age, and endorsement of materialistic values as predictors. British Journal of Psychology, 96(4), 467-91.

Dole, C., \& Schroeder, R. G. (2001). The impact of various factors on the personality, job satisfaction and turnover intentions of professional accountants. Managerial Auditing Journal, 16(4), 234-245.

Emamipour, S., \& Sabzmeydani, P. (2009). The relationship between personality characteristics and perfectionism with university students' general health. Journal of Psychological Studies, 2(5), 95-106.

Ergin, E. A. (2010). Compulsive buying behaviour tendencies: The case of Turkish consumers. African Journal of Business Management, 4(3), 333-338.

Faber, R. J., \& Christenson, G. A. (1996). In the mood to buy: Differences in the mood states experienced by compulsive buyers and other consumers. Psychology \& Marketing, 13(8), 803-819.

Faber, R. J., \& O'Guinn, T. C. (1989). Classifying compulsive consumers: Advances in the development of a diagnostic tool. In Srull TK (Eds.), Advances in consumer research (738-744). Provo, UT: Association for Consumer Research.

Faber, R. J., O'Guinn, T. C., \& Krych, R. (1987). Compulsive consumption. Advances in consumer research, 14(1), 132135.

Frankel, F., Myatt, R., Cantwell, D. P., \& Feinberg, D. T. (1997). Parent assisted children's social skills training: Effects on children with and without attention-deficit hyperactivity disorder. Journal of the Academy of Child \& Adolescent Psychiatry, 36, 1056-1064.

Gohary, A., \& Heidarzadeh Hanzaee, K. (2014). Personality traits as predictors of shopping motivations and behaviours: A canonical correlation analysis. Arab Economics \& Business Journal, 9(2), 166-174.

Goldberg, D. P., \& Hillier, V. F. (1979). A scaled version of the general health questionnaire. Psychological Medicine, 9, $139-145$

James, A., \& Roberts Camille, R. (2012). Stress, gender and compulsive buying among early adolescents. Young Consumers, 13(2), 113-123.

Karaś, D., Cieciuch, J., \& Keyes, C. L. M. (2014). The polish adaptation of the Mental Health Continuum-Short Form (MHC-SF). Personality \& Individual Differences, 69, 104-109.

Koran, L. M., Faber, R. J. Aboujaoude, E., Large, M. D., \& Serpe, R. T. (2006). Estimated prevalence of compulsive buying behaviour in the United States. The American journal of Psychiatry, 163, 1806-1812.

Lee, Y. K., Chang, C. T., Lin, Y., \& Cheng, Z. H. (2014). The dark side of smart phone usage: Psychological traits, compulsive behaviour and technostress. Computers in Human Behavior, 31, 373-383.

Maddi, S. R. (1989). Personality theories: A comparative analysis. Pacific Grove, CA: Brooks/ColePublishing Company.

McCrae, R. R., \& Costa, P. T. Jr. (1989). Rotation to maximize the construct validity of factors in the NEO Personality Inventory. Multivariate Behavioral Research, 24, 107-124.

Moynihan, L. M., \& Peterson, R. S. (2001). A contingent configuration approach to understanding the role of personality in organizational groups. Research in Organizational Behavior, 23, 327-378.

Sadock B. J.., \& Sadock, V. A. (2007). Kaplan \& Sadock's concise textbook of clinical psychiatry. Philadelphia: Lippincott, Williams \& Wilkins.

Sadock, B. J., Kaplan, H. I., \& Sadock, C. A. (2007). Kaplan \& Sadock’s synopsis of psychiatry: Behavioral sciences/clinical psychiatry $\left(10^{\text {th }}\right.$ ed.). Philadelphia: Wolter Kluwer/Lippincott Williams \& Wilkins.

Sappington, A. A., Pharr, R., Tunstall, A., \& Rickert, E. (1997). Relationships among child abuse, date abuse, and psychological problems. Journal of Clinical Psychology, 53, 319-29.

Saraneva, A., \& Sääksjärvi, M. (2008). Young compulsive buyers and the emotional roller-coaster in shopping. Young Consumers: Insight and Ideas for Responsible Marketers, 9(2), 75-89.

Silvera, D. H., Lavack, A. M., \& Kropp, F. (2008). Impulse buying: The role of affect, social influence, and subjective wellbeing. Journal of Consumer Marketing, 25(1), 23-33. 
Taherikia, F., \&Naderi, A. (2012). Identifying and evaluating factors affecting compulsive buying (addiction to buying). Researcher of Journal of Management, 9(26), 87-106.

Veludo-de-Oliveira, T. M., Augusto Falciano, M., \& Villas Boas Perito, R. (2014). Effects of credit card usage on young Brazilians' compulsive buying. Young Consumers, 15(2), 111-124.

White, L. A., Newman, M. C., Cromwell, G. L., \& Lindemann, M. D. (2002). Brewers dried yeast as a source of mannan oligosaccharides for weanling pigs. Journal of Animal Science., 80(10), 2619-2628.

Ye, S., Yu, L., \& Li, K. K. (2012). A cross-lagged model of self-esteem and life satisfaction: Gender differences among Chinese university students. Personality and Individual Differences, 52(4), 546-551.

Zargar, S. S., 2013. A Study of Personality Characteristics of Higher Secondary Teachers. International Journal of Educational Research, 1(2), 16-21. 